\title{
RIGHT VENTRICLE HYDATID CYST WITH A PERICARDIAL CAVITY INVOLVEMENT: A CASE REPORT
}

\author{
Plamen Panayotov ${ }^{1,2}$, Radoslava Boyadzhieva ${ }^{2}$, Vladimir Kornovski ${ }^{3}$, Yavor Peychev ${ }^{1}$, \\ Daniela Panayotova ${ }^{2}$, Veselin Petrov ${ }^{3}$ \\ ${ }^{1}$ Department of Cardiology and Rheumatology, Medical University of Varna \\ ${ }^{2}$ Division of Cardiac Surgery, St. Marina University Hospital of Varna and \\ ${ }^{3}$ Department of Vascular Surgery, Medical University of Varna
}

\begin{abstract}
The echinococcal disease with a cardiac location of the hydatid cyst is uncommon and potentially fatal for the patient's life. The diagnosis could be difficult because no specific symptoms ever occur. However, this pathology should be always kept in mind in endemic regions. Herein we report a rare case of hydatid cyst situated in the right ventricular free wall. The diagnosis was ensured by transthoracic and transesophageal echocardiography, CT and MRI. The patient underwent a total cardiopulmonary bypass without aortic cross-clamping. Several ruptured daughter cysts were removed. The fibrous capsule was opened and the germinative membrane was extirpated. Postopepatively, albendazole therapy was administered. No complications were reported.
\end{abstract}

Key words: echinococcal disease, hydatid cyst, right ventricular wall

\section{INTRODUCTION}

The human cystic echinococcosis is a parasitic disease most often caused by the larval stage of the Echinococcus granulosus. For the period of 1983 till 1995 its incidence in Bulgaria was measured to be 3.3 per 100000 (16). Nowadays it still presents an important health problem in our country as well as in the Mediterranean basin (especially parts of Spain, southern Italy and Sardinia, where annual incidence rates in human reach 4-8/100000), and the sheep raising areas of Great Britain (12). Hydatid cysts with a cardiac location are sporadic (about $0,5-2 \%$ of all

Address for correspondence:

Plamen Panayotov, MD

Division of Cardiac Surgery,

St. Marina University Hospital of Varna,

1 Hristo Smirnenski Str., 9010 Varna, Bulgaria

e-mail:pl.panayotov@gmail.com

Received: November 4, 2013

Accepted: November 22, 2013 human hidatidosis) $(1,6)$. The right ventricle is only rarely involved accounting for $8 \%$ of cases (13). We report a case of hydatid cyst situated in the right ventricle free wall.

\section{CASE REPORT}

A 70-year-old woman was hospitalized with symptoms of persistent cough accompanied by copious white liquid expectoration, dyspnea and chest pain. Her medical history didn't reveal anything unusual. She was not taking medication. The patient lives in the country side breeding animals and has a pet-dog. The examination of her status showed: an orthopneic position in bed, no fever, small engorgement of the neck veins, rhythmic heartbeat, pulse rate $92 / \mathrm{min}$, blood pressure $120 / 80$. There were no complaints of abdominal pain, no peripheral enlarged lymph nodes. Laboratory blood test did not show any blood-cell count abnormalities, inflammatory syndrome or abnormalities of the liver function. On ECG examination a T-wave negativity in all precordial leads and single ventricular extrasystoles 
Plamen Panayotov, Radoslava Boyadzhieva, Vladimir Kornovski et al.

were noticed. The chest x-ray revealed normal cardiac outlines. On TTE study a small pericardial effusion $<100 \mathrm{ml}$ and a nonhomogenous cyctic mass were detected. It was adjacent to the right ventricular free wall with a protrusion towards the pericardial cavity. The CT and the MRI confirmed the presence of the lesion and determined its myocardial origin. The formation was spherical with a well defined capsule and intracystic membranes (Fig. 1 and Fig. 2). The suspicion of cardiac hydatidosis was confirmed by serological tests (ELISA and immunofluorescence IFA). The possibility of an intracardiac tumor as a DD was then eliminated. No other organs were affected. The patient was referred for surgical intervention.

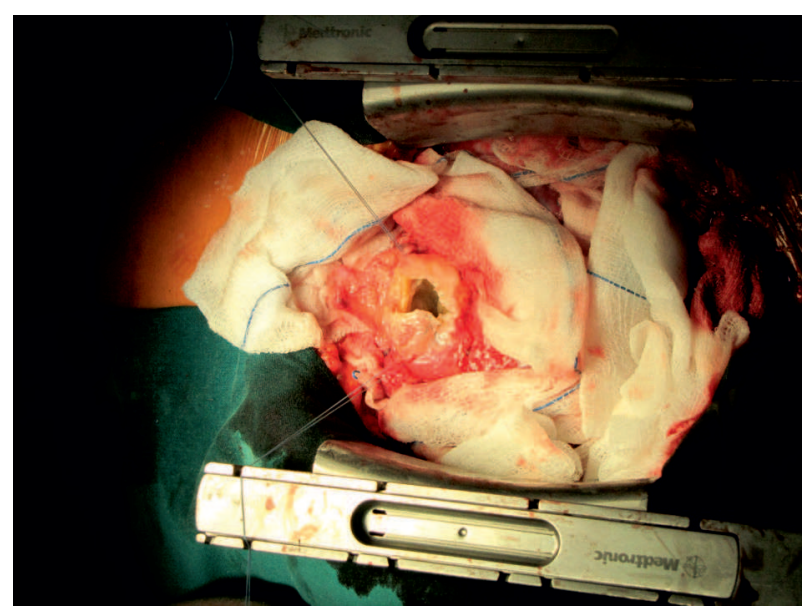

Fig.1. The right ventricular wall with hydatid cyst opened (yellow colored) is visible

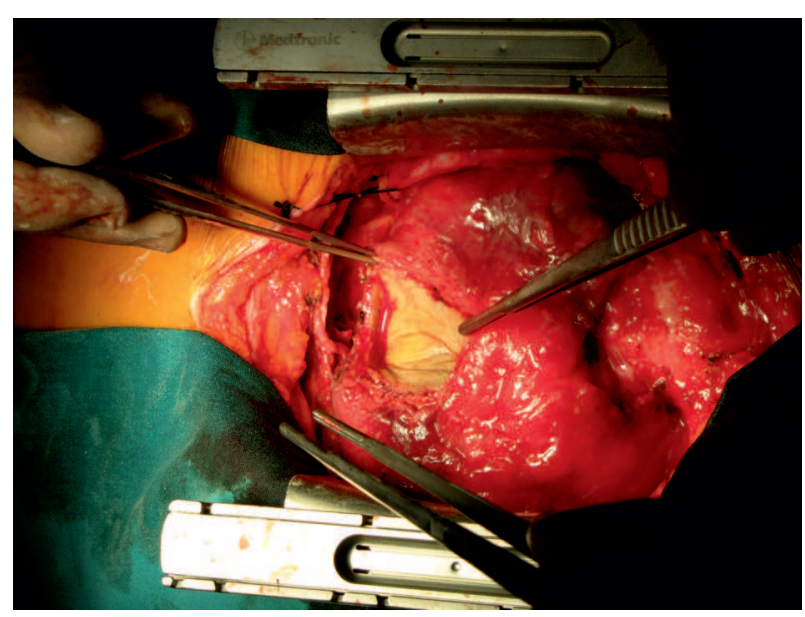

Fig.2. Inner surface of the cyst (yellow colored) is visible on the picture

A medial sternotomy followed by a pericardiotomy were performed. A total cardiopulmonary by- pass without cross-clamping was initiated. Massive adhesions between the heart and the pericardium were removed. The cystic mass was found located on the right ventricle front wall, partially covering the diaphragmatic surface. The operative field was protected by gauze bandages soaked in hypertonic saline solution at $30 \%$. Several ruptured daughter cysts were removed. The fibrous capsule was intact. We opened it and extirpated the germinative membrane. The residual cavity walls where then resected and treated with antiseptics and scolicidal solution (hypertonic saline). The patient was gradually weaned from the CPB. Pathologic and microbiologic examination of the surgical material confirmed the diagnosis of hydatid cyst.

The postoperative period was uneventful, after 7 days she was discharged and an Albendazole therapy was prescribed. Her follow-up period continues and she has a check-up in every 3 months by a cardiac ultrasound.

\section{DISCUSSION}

The life cycle of Echinococcous granulosus is almost exclusively domestic, involving dogs as definitive and (predominantly) sheep as intermediate hosts (12). Human beings could also become intermediate hosts by eating insufficiently cooked food or drinking water contaminated with dog feces. Our patient raises cattle and has a dog which may be helpful in diagnostic point of view. Echinococcosis in humans results from the expansion of parasitic cysts in the visceral organs. It affects mostly the liver (50$70 \%)$ and the lung (20-30\%) (7). Cardiac location is infrequent. Larvae reach the right atrium by the return venous system. After that via the pulmonary circulation or by the way of a patent foramen ovale they pass through the coronary arteries and lodge the myocardium (15). When this occurs, the left ventricule is the most frequently involved site (60\%), followed by the right ventricle (15\%), the interventrcular septum (9\%), the left atrium (8\%), the right atrium (4\%) and the interatrial septum (2\%). Primary pericardial cysts are extremely rare and they generally develop secondary to intrapericardial rupture of a myocardial cyst or to spillage of cysts' contents during surgical removal $(5,14)$. Hydatid cysts expand slowly (around 1-5 years) (9). 
That is the reason why only about $10 \%$ of the patients especially those with large hydatid cysts have clinical manifestations (10). As cysts grow, they are pushed toward a weaker side of the cardiac wall either the epicardium or the endocardium (17). Subepicardial cysts grow more easily toward the pericardial cavity and can attain large diameters, as it is in our case where during the surgery the cyst was measured to be $7 \times 7 \mathrm{~cm}$ in dimension. Its eventual rupture may lead secondary pericardial dissemination, acute pericarditis, constrictive pericarditis or even pericardial tamponade. On the other hand the intracavitary rupture of subendocardial cyst could cause a pulmonary or peripheral systemic embolism, an anaphylactic reaction and sudden death $(2,11,17)$. Depending on the site, size, number and integrity of the tumor symptoms are variable and atypical: from pericardial and retrosternal chest pain, dyspnea, asystolic murmur, valvular syndrome, rash, fever, nausea, vomiting, congestive heart failure, acute stoke, acute respiratory distress, acute abdomen to, as we mentioned above, a sudden death. According to this Echinococccous disease could closely mimic coronary artery disease, valvular heart disease, conductions disturbances, pericarditis and myocardial infarction. The establishment of the right diagnosis is crucial for avoiding the potentially lethal complications.

ECG often displays inverted $\mathrm{T}$ waves, which were also observed on the cardiogram of our patient, or right bundle branch blocks but these changes are not specific. Moreover the ECG could be fully normal. On chest X-ray, localized deformities of the cardiac silhouette may be absent (3). In our patient the hydatid cyst was seen first on a $2 \mathrm{D}$ dimensional ultrasound. Echocardiography is an effective technique that facilitates a quick and easy anatomical and topographic diagnosis, as well as the typical aspect of the cyst. It can also inform about the ventricular function and cardiac hemodynamic status (8). In addition we used CT and MRI in order to precise the lesion extension, its surrounding tissue involvement and its nature. The coronary angiography and TEE are helpful diagnostic methods which could be used in cases suspected for an atrial or great blood vessel involvement. Medical therapy of inoperative cysts with either Albendazole or Mebendazole produces improvements in most patients but the cure rate is approximately $33 \%$ (7). We believe that cardiac hydatid cysts should be treated by surgical excision. Resection under cardiopulmonary bypass, since 1962, has been considered the safest method, with the least risk of spillage of cyst contents during the procedure (5). In operations for cysts, that are located in the right side of the heart, the pulmonary artery can be clamped in order to avoid pulmonary embolism. In our case there was no reason to perform it because the cyst was intact, extended towards the pericardial cavity without intraventricular penetration. It has been suggested that antihelmintics (Mebendazole or Albendazole) should be given during the postoperative period because of the risk of vascular implantation and embolization (4).

\section{CONCLUSION}

In conclusion we could say that although uncommon and more often asymptomatic, cardiac hydatid disease must be considered in the diagnosis of cardiac tumor (thrombus, myxoma, sarcoma) especially in endemic regions and primarily when the patient's clinical history reveals an undergone surgery as a treatment of previous cysts in the same or in other organs.

\section{REFERENCES}

1. Abid, A., S. Ben Omrane, K. Kaouel. Intracavitary cardiac hydatid cyst.- Cardiovasc. Surg., 11, 2003, 521-525.

2. Bayezid, O., A. Ocal, O. Isik. A case of cardiac hydatid cyst localized on the interventricular septum and causing pulmonary emboli. J. Cardiovasc. Surg. (Torino), 32, 1991, 3, 324-326.

3. Ben-Hamda, K., F. Maatouk, M. Ben-Farhat. Eighteen-year experience with echinococcosus of the heart: clinical and echocardiographic features in 14 patients.-International Journal of Cardiology, 91, 2003, 2-3, 145-151.

4. Durgut, K., U. Ozergin, K. Ozdemir. Hydatid cyst on right ventricular posterior wall.- Asian Cardiovasc. Thorac. Ann., 8, 2000, 275-277.

5. Hafize Yaliniz, A. Tokcan, O. K. Salih. Surgical treatment of cardiac hydatid disease: a report of 7 cases. Tex. Heart Inst. J., 33, 2006, 333-339. 
6. Kaplan, M., M. Demirtas, S. Cimen. Cardiac hydatid cysts with intracavitary expansion.- Ann. Thorac. Surg., 71, 2001, 5, 1587-1590

7. Kardelen, F., G. Akcurin, H. Ertug. Right atrial hydatid cyst with multiple organ involvement.- Asian Cardiovasc. Thorac. Ann., 9, 2001, 240-242.

8. Kirova, G., V. Velchev, G. Hinkov. Right ventricular echinococcosis followed by hydatid pulmonary embolism.- European Journal of Radiology Extra, 48, 2003, 63-66.

9. Macedo, A. J., M. P. Magalhaes, N. J. Tavares. Cardiac hydatid cyst in a child.- Pediatr. Cardiol., 18, 1997, 226-228.

10. Miralles, A., L. Bracamonte, A. Pavie. Cardiac echinococcosis: surgical treatment and results.- J. Thorac. Cardiovasc. Surg., 107, 1994, 184-90.

11. Perez-Gomez. F., H. Duran, S. Tamames. Cardiac echinococcosis: clinical picture and complications.Br. Heart J., 35, 1973, 12, 1326-1331.
12. Romig, T., A. Dinkel, U. Mackenstedt. The presence situation of echinococcosis in Europe- Parasitology Internetional, 55, 2006, 187-191.

13. Rossouw, G. J., C. J. Knott-Craig, P. E. Erasmus. Cardiac echinoccosis: cyst removal in a beating heart.- Ann. Thorac. Surg., 53, 1992, 328-329.

14. Salih O.K., S. K. Celik, M. S. Topcuoglu. Surgical treatment of hydatid cysts of the heart: a report of 3 casesand a review of the literature.- Can. J. Surg., 41, 1998, 321-7.

15. Tejeda, J. G., J. Saavedra, L. Molina. Hydatid disease of the interventricular septum causing pericardial effusion. Ann. Thorac. Surg., 71, 2001, 2034-2036.

16. Todorov, T., V. Boeva. Human echinococcosis in Bulgaria: a comparative epidemiological analysis.Bull WHO, 77, 1999, 2, 110-118.

17. Tuncer, E., S. Tas, I. Mtataraci. Surgical treatment of cardiac hydatid disease in 13 patients.- Tex. Heart Inst. J. 37, 2010, 2, 189-193. 